\title{
Tantangan TV lokal di era disrupsi media
}

\author{
Nanang Yulianto Romadlono ${ }^{1 *}$, Yofiendi Indah Indainanto ${ }^{2}$ \\ 1,2 Universitas Diponegoro Semarang
}

\begin{abstract}
Television broadcasting media during the Disruption Era was the biggest challenge for Television, especially local television to innovate and be creative in the era of technological development. Competition between the media is very tight coupled with the current Covid 19 pandemic, requiring media companies to survive in the competition of competitors. Cakra Semarang TV as Local TV in Central Java in an effort to compete in the Age of Media Disruption. The method used in this research is interpretive qualitative, using the theory of Sociocultural Evolution and Socio-technical System Theory that is used to see Cakra Semarang TV survive the media disturbances. the findings of the research show that creativity, promotional content and news as well as the application of media are the benefits that are utilized by Cakra Semarang TV to stay afloat. The application of Media Divergence by Cakra Semarang TV is a solution to the change in the way viewers watch the previously conventional Cakra Semarang TV program, but now viewers can enjoy Cakra Television Semarang TV broadcasts boldly or online. Efforts to save Cakra Semarang TV in a program broadcasting broadcast programs with the concept of divergence using YouTube streaming, social media to the site portal to get closer to the audience. This effort was carried out by Cakra Semarang TV as a way to maintain existence in the Local Television Media industry in Central Java in the Era of Disruption Current media.

Keyword : Cakra semarang tv, disruption, divergence, media challenges

Abstrak: Disrupsi menjadi tantangan terbesar bagi televisi lokal dalam menghadapi era perkembangan zaman dan teknologi yang mengarah ke dunia digital. Kompetisi antar media sangat ketat ditambah dengan masa pandemi Covid 19 saat ini mengharuskan perusahaan media untuk survive dalam menghadapi kompetitor. Penelitian ini bertujuan menganalisis tantangan yang dihadapi serta upaya Cakra Semarang TV sebagai TV Lokal di Jawa Tengah dalam upaya bersaing di Era Disrupsi Media. Penelitian deskriptif kualitatif ini dalam pengumpulan data dilakukan dengan wawancara dan dokumentasi. Hasil temuan peneliti menunjukan, kreatifitas, inovasi konten hiburan dan berita serta penerapan divergensi media menjadi upaya yang di manfaatkan oleh Cakra Semarang TV agar tetap survive. Penerapan Divergensi Media oleh Cakra Semarang TV adalah upaya solusi terhadap perubahan cara pemirsa dalam menonton tayangan program acara televisi Cakra Semarang TV yang sebelumnya secara konvensional, namun sekarang audience dapat menikmati siaran Televisi Cakra semarang TV secara daring atau online. Upaya efektivitas Cakra Semarang TV dalam penyebarluasan siaran program acara dengan konsep divergensi yakni menggunakan streaming youtube, media sosial hingga portal website untuk mendekatkan diri ke audiencenya. Upaya tersebut dilaksanakan Cakra Semarang TV sebagai cara dalam mempertahankan eksistensi dalam industri media televisi Lokal di Jawa Tengah pada era disrupsi media saat ini.
\end{abstract}

Kata Kunci: Cakra semarang tv, disrupsi, divergensi, tantangan media.

"Corresponding Author: Nanang Yulianto Romadlono | nanangyulianto17@gmail.com | Universitas Diponegoro, Jl. Erlangga Barat 7 No.33, Pleburan, Semarang, Indonesia 


\section{Pendahuluan}

Stasiun televisi lokal Cakra Semarang TV atau Semarang TV Channel 52 UHF merupakan TV Lokal Jawa Tengah berdiri di kota Semarang. Era distrupsi media berdampak pada eksistensi Cakra Semarang TV yang dituntut untuk melakukan inovasi dan perluasan penyebaran konten dengan cara memanfaatkan dunia digital seperti media sosial. Perkembangan komsumsi konten oleh audines yang mengarah pada konsumsi digital, mendorong proses produksi semakin beragam yang tidak hanya untuk kebutuhan konten konvensional, melainkan konten digital (straming, dan youtube). Upaya tersebut dinilai untuk meningkatkan efektivitas ditengah distrupsi. Perkembangan media sangat dipengaruhi aspek teknologi dalam membentuk karaterisitik dan periodisasi perkembangan media saat ini (Saptya \& Permana, 2029).

Cakra Semarang TV yang menghadirkan saran-siaran lokal seputar Jawa Tengah, turut mengalami perubahan media yang disebapkan adanya internet. Televisi sekarang tidak terpaku pada jam tayang, hal tersebut disebapkan adannya perubahan pola menonton (Abdullah \& Puspitasari, 2018). Temuan (Rusadi, 2014) yang melihat pola dalam mengkonsumsi berita antara media konvensiona dan internet menunjukan masyarakat digital native banyak mengkonsumsi media berbasis internet sementara digital settler dan imigran memiliki intesitas yang lebih banyak dibanding digital native. Artinnya pangsa pasar media konvensional mengalami pergeseran. Cakra Semarang TV harus memahami bagaimana pangsa penonton sangat mempengaruhi eksistensi media.

Menurut data Hootsuite (We are Social) 2020, di Indonesia dengan total populasi 272,1 juta, pengguna internet mencapai 175,4 juta, dan pengguna media Sosial Aktif: 160 juta. Rata-rata setiap hari waktu melihat televisi (broadcast, streaming dan video tentang permintaan) 3 jam, 4 menit. Artinya internet telah merubah cara seseorang bekerja, mendapatkan informasi, dan menghabiskan waktu. perkembangan tersebut berdampak pada media terkoneksi internet digunakan untuk mengkonsumsi media televisi berbasi digital. Hal tersebut menyebapkan terjadinya disrupsi atau gangguan ini terjadi karena perubahan teknologi dan inovasi yang mengikutinya.

Banyak perusahaan-perusahan media yang bergeser dan menaruh perhatian besar terhadap teknologi internet untuk meningkatkan pesaingan dan eksistensi, tidak terkecuali Semarang tv. Perubahan tersebut tidak menjamin media dapat mempertahankan kedudukan dan mendapatkan keuntungan, karena kondisi dunia digital jauh berbeda dengan dunia pertelevisian.

Peningkatkan konsumsi digital, mendorong Cakra Semarang TV berinovasi dalam upaya menarik pembaca. Produksi konten berita dan hiburan media Cakra Semarang TV awalnya disiarkan secara analog sesuai dengan coverage area melalui kanal 52 
UHF menjadi tantangan dengan mengandalkan siaran terrestrial untuk menyebarkan konten. upaya pemanfaatan media digital terus diupayakan pengelola media penyiaran dilakukan sebagai salah satu strategi menarik audiens melalui Streaming youtube, portal website dan media applikasi streaming Cakra Semarang TV.

Stasiun televisi Cakra Semarang TV yang merupakan salah satu stasiun televisi lokal Jawa Tengah harus mampu beradaptasi dengan hadirnya teknologi penyiaran digital ( media baru ) di era disrupsi media dengan perubahan keadaan di dunia industri penyiaran Indonesia. Perubahan dengan adanya distrupsi media juga terjadi di media televisi lokal. Temuan (Halim \& Sujoko, 2018) pada Stasiun tv9 Lombok menerapkan divergensi untuk menjawab perubahan menonton siaran televisi dari konvensional ke siaran

televisi secara daring. Pola menonton TV pun telah berubah dengan tidak terpaku dengan jam siaran dan waktu siaran. Era internet orang bisa menonton TV kapan saja dan dimana, serta menonton tidak menggunakan televisi melainkan gawai, smartphone atau laptop (Abdullah \& Puspitasari, 2018). Perubahan juga terjadi di LPP TVRI dengan upaya perbaikan kualitas brand TVRI, mulai dari kanal 4 sport menjadi High Definition (HD), SDM. Untuk mendapat kepercayaan dari stakeholders, TVRI menjalankan aktivitas good governance dengan memiliki PPID baik secara luring maupun daring (Ramadhanty, 2019).

Penelitian ini ingin mengetahui bagaimana proses adaptasi yang terjadi pada Cakra Semarang TV terhadap perubahan teknologi penyiaran digital. Lebih lanjut penelitian ini juga ingin mengetahui tantangan dan peluang yang muncul dalam proses adaptasi Cakra Semarang TV. Penelitian ini bertujuan untuk mengetahui perubahan-perubahan yang digunakan Cakra Semarang TV sebagai stasiun televisi Lokal Jawa Tengah menghadapi tantangan dan peluang media di era disrupsi media.

\section{Tinjauan pustaka}

\section{Disrupsi Media}

Penggunaan internet dalam mengonsumsi konten media televisi menyebabkan disrupsi media. Disrupsi atau gangguan ini terjadi karena perubahan teknologi dan inovasi yang mengikutinya. Istilah disrupsi (Disruption) awalnya diperkenalkan oleh Clayton M. Christensen dalam jurnalnya,The Innovator's Dilemma : When New Technologies Cause great Firms to Fail (1997). Disruption berasal dari kata disruptive inovation yang diartikan sebagai gangguan inovasi terhadap inovasi. Sebut penggunaan alat produksi yang baru untuk kuliatas gambar yang baik, bergeser penggunaan alat yang terhubung dengan internet untuk konektivitas yang mengarah pada produksi konten yang cepat. Akibatnnya sejumlah perusahaan media mengalami pergeseran oleh perubahan teknologi. Pola konsumsi media televisi sekarang dapat menggunakan perangkat yang terhubung ke internet. Penggunaan internet dalam mengonsumsi konten media televisi menyebabkan terjadinnya disrupsi. Disrupsi atau gangguan ini terjadi karena perubahan teknologi dan inovasi yang mengikutinya. Disrupsi berarti inovasi yang menguntungkan, 
bukan karena suatu perusahaan memiliki highly regulated procedures, melainkan karena penyangkalan (deception) atau pengabaian terhadap apa yang dianggap remeh (Ohoitimur, 2018).

Pemanfaatan teknologi dan inovasi juga dilakukan oleh perusahaan dalam mempertahankan eksistensinya, namun di sisi lain hadirnya disrupsi inovasi dan teknologi membuka peluang perubahan yang sulit diprediksi sebelumnya oleh perusahaan yang memimpin pasar. Sejumlah perusahaan yang tergeser oleh perubahan teknologi pola konsumsi media juga berubah, seperti menerima konten informasi yang digunakan lebih baru dari sebelumnya. Disruption era merupakan periode saat inovasi pada masa lalu akan digantikan dengan beragam inovasi baru, yang awalnya dilihat hanya sebatas pengembangan kreatifitas, namun lambat laun inovasi baru ini secara berangsur-angsur menggantikan inovasi lama dengan adannya perkembangan teknologi serta perubahan kebutuhan masyarakat yang dinamis. Disrupsi atau gangguan terhadap inovasi ini akhirnya membuat seluruh bidang usaha mengalami perubahan yang cepat, dan digantikan dengan inovasi terkini dalam menyempurnakan inovasi sebelumnya. Era disrupsi ini harus dilihat oleh pengelola media penyiaran untuk menyusun langkah strategis agar dapat menyesuaikan dengan perkembangan lingkungan yang terus berubah. Menurut (Christensen, 1997), teori disrupsi/ gangguan inovasi adalah bagaimana perusahaan berjuang dengan jenis inovasi tertentu dan bagaimana perusahaan bisnis dapat diprediksi berhasil dalam inovasi yang didukung oleh teknologi yang sesuai dengan perkembangan zaman yang dinamis. Hal tersebut yang memunculkan distrupsi (Halim \& Sujoko, 2018).

Pelaku bisnis harus menggunakan strategi yang tepat untuk menghadapi kemungkinan gangguan (disrupsi) dari kompetitor baru yang menggunakan teknologi terkini. Beberapa faktor yang mesti dilakukan adalah (1). Selalu memikirkan kepentingan audiens, (2). mempersiapkan cara untuk mengatasi disrupsi yang mungkin terjadi, (3). Memahami peran budaya, (4). Mengevaluasi sumber daya yang dimiliki, (5). Mengevaluasi pola interaksi menuju efesiensi, (6). Melakukan penetapan prioritas tindakan. Hal inipun terjadi pada perusahaan media tradisional dalam Menghadapi tantangan besar dari media digital terutama dengan hadirnya internet (new media).

Bagi media konvensional dengan adannya disrupsi menimbulkan efek yang beragam, mulai dari begesernnya konsumsi audien (konvensional ke digital), penggunaan teknologi baru dalam produksi, merubah cara kerja, dan orentasi terhadap pasar (iklan) yang turut bergeser ke digital. Tentunnya efek ini menjadi perhatian serus media konvensional dalam menghadapi distupsi media.

\section{Metode}

Penelitian ini menggunakan metode deskriptif kualitatif. Objek penelitian CakraTV Semarang. Dalam penelitian ini, teknik pengumpulan data berupa wawancara pihak-pihak Cakra Semarang TV yang tediri dari Medi Harmoko staf redaksi, Agung Mujiono Manajer teknik, dan Supriyadi Menejer produser program. Narasumber dipilih 
berdasarkan kemampuan dan pengalaman yang telah lama berkecimpung di Cakra Semarang TV. Peneliti juga menggunakan data sekunder berupa dokumentasi untuk mendukung data primer yang didapatkan.Penelitian ini menggunakan metode deskriptif kualitatif. Objek penelitian CakraTV Semarang. Dalam penelitian ini, teknik pengumpulan data berupa wawancara pihak-pihak Cakra Semarang TV yang tediri dari Medi Harmoko staf redaksi, Agung Mujiono Manajer teknik, dan Supriyadi Menejer produser program. Narasumber dipilih berdasarkan kemampuan dan pengalaman yang telah lama berkecimpung di Cakra Semarang TV. Peneliti juga menggunakan data sekunder berupa dokumentasi untuk mendukung data primer yang didapatkan.

\section{Hasil dan pembahasan}

Proses Produksi Cakra Semarang TV

Cakra Semarang TV menghadapi tantangan yang sulit terutama dari kompetitor media lokal, nasional dan media baru (online) dalam menghadapi pangsa pasar. Efektivitas produksi konten dilaksanakan dengan menggunakan konvergensi media. Menurut Supriyadi Produser Program, Cakra Semarang TV saat ini masih menggunakan sistem anolog yang mengarah pada proses digital. Menurut Weber \& Newberry (Weber \& Newberry, 2007), TV digital memberikan keuntungan mulai dari, peningkatan kualitas, pilihan audio yang banyak, dapat dikoneksikan dengan personal, tersedianya Random Acces Storage yang memungkinkan akses lebih cepat, dan Time Shifting (pelanggan dapat memberikan respon secara langsung) (Agung, 2012). Meski menggunakan sistem Analog, Cakra Semarang TV menggunakan perangkat-

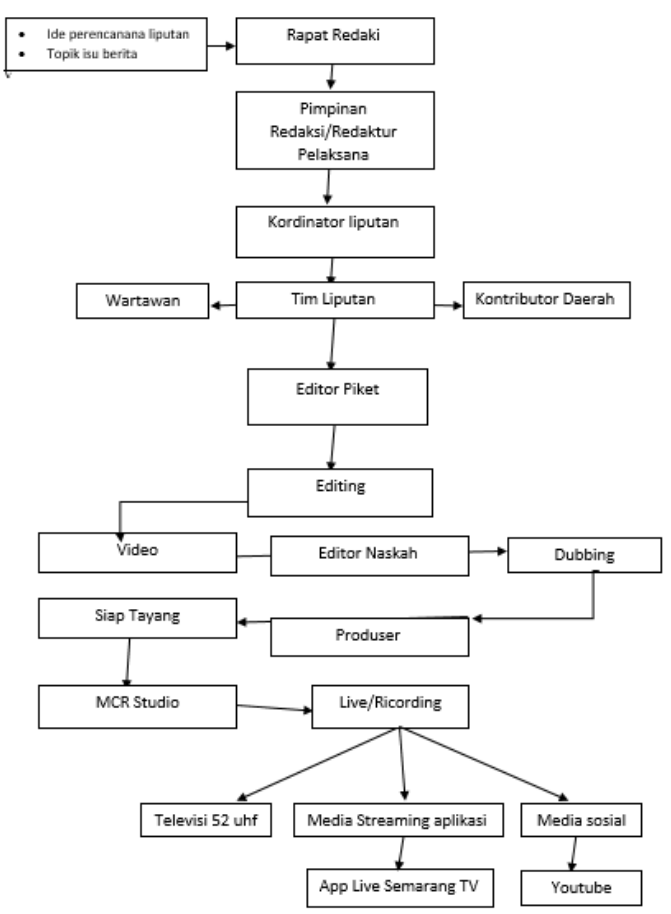

perangkat yang baik. Siklus dari industri media televisi yakni dengan memproduksi program acara. Proses produksi seperti bagan dibawah.

Tahap awal produksi bermulai adanya rencana liputan, isu, konten yang diproduksi baik konten berita maupun hiburan. Setiap ide dan rencana liputan dibahas dan ditentukan dalam rapat redaksi. selanjutnya pimpinan redaksi menentukan proses liputan melalui kordinator liputan yang bertugas bertanggung jawab terhadap kordinasi wartawan dilapangan. Tim liputan yang bekeja mengambil gambar teridiri dari wartawan yang ditugas untuk meliput aktivitas di lapangan, dan kontributor yang bertugas memberi berita dari daerah-daerah sekitar. Selanjutnya untuk menseleksi gambar dan berita masuk agar layak diproses selanjutnya ada 
editor piket yang mengecek berita masuk, kelengkapan narasi dan video, serta kelayakan konten, untuk masuk ke proses editing yang meliputi video, editor naskah, dan dubbing. Kemudian konten yang telah siap akan di cek kembali oleh produser acara yang bertanggung jawab terhadap keseluruhan konten ditampilkan. Konten yang layak tayang akan masuk proses penayangan melalui Master control room (MCR) yang akan ditayangkan secara live ataupun ricording.

Sebelumnya Cakra Semarang TV hanya menampilkan konten di frekuensi 52 uhf analog, namunya dengan adanya perkembangan internet, Cakra Semarang TV melebarkan siaran melalui aplikasi streaming live Semarang TV, dan media sosial Youtube. Adanya perluasan siaran ke aplikasi streaming dan youtube, turut merubah cara konten dan cara audiens mengkonsumsi konten. kemapuan media yang mampu menyimpan hasil siaran, mempermudah audiens mengkonsumsi konten. Menurut Flew (2005), informasi digital bersifat manipulable, dapat diubah dan disesuaikan mulai dari proses penciptaan, penyimpanan, pengiriman, dan penggunaan yang bersifat networkable maupun compressible (Karman, 2017).

Program acara Cakra Semarang TV berada dibawah divisi pemberitaan dan produksi. Kedua divisi tersebut harus bekerjasama dengan divisi teknis dalam menyiarkan konten program acara Televisi. Peran seorang produser, kameraman, reporter, grafis, master control room, presenter memiliki fungsi yang penting dalam kelancaran produksi konten program acara Televisi. Cakra TV Semarang divisi pemberitaan membutuhkan bantuan dari MCR
(Master Control Room) untuk menayangkan paket berita yang sudah dibuat oleh divisi redaksi. Dalam Divisi redaksi reporter juga membutuhkan kameraman serta editor dalam membuat sebuah konten pemberitaan yang siap untuk ditayangkan. Cakra Semarang TV menggunakan siaran analog dengan kanal 52 UHF. Seiring berkembangnya teknologi saat ini serta daya jangkau yang terbatas Cakra Semarang TV menggunakan kanal streaming atau youtube dalam menyebarluaskan konten siarannya. Dengan memanfaatkan media baru youtube bertujuan agar masyarakat dapat mengakses siaran dan berlangganan (subscribe) program acara Cakra Semarang TV kapan saja dan dimanapun. Kebijakan media lama melakukannya tidak hanya meminjam materi dari media baru karena tren saja, tetapi juga karena faktor ekonomi yang terlibat yaitu mengurangi biaya produksi. Artinya Youtube menjadi sarana memberikan kemudahan bagi produser televisi untuk konten dan beban biaya produksi.

Perkembangan Program Cakra Semarang TV

Kompleksitas industri media televisi lokal melibatkan banyak faktor termasuk dalam proses distribusi dan pemrograman dengan terbatasnya segmentasi pasar. Cakra Semarang Tv memiliki ciri khas konten dalam mempengaruhi pola konsumsi informasi di seputar Jawa Tengah. Kekuatan televisi yang mampu membangun identitas mendorong setiap acara harus mencerminkan identitas daerah sebagai identitas televisi. Stasiun Cakra Semarang TV mengemas identitas melalui format program acara yang 
semata-mata menekankan pada hiburan (budaya) dan berita-berita. tabel dibawah memperlihatkan program acara yang rutin disiarankan selama lebih dari empat hari di Cakra Semarang TV. Menurut Medi Harmoko staf redaksi Cakra Semarang TV (2020) bahwa porsi konten pemberitaan sekitar $40 \%$ dan konten hiburan sebesar 60\%. Agung Mujiono manajer teknik menjelaskan sejak awal tahun 2015 pihaknya telah menggunakan kanal youtube dalam menyebarluaskan konten siaran. Memanfaatkan paltfrom sangat berguna bagi audines mendapatkan informasi dengan cepat. Hal tersebut sebagai upaya alternatif untuk menambah jumlah pemirsa atau viewer dalam menggunakan perangkat yang tersedia (Halim, 2018).

Menurut Manajer Teknik Agung Mujiono menjelaskan Cakra Semarang TV (2020) menggunakan beragam media untuk menyampaikan pesan kepada masyarakat mulai dari Streaming Youtube, website semarangtv.tv, media sosial seperti facebook dan instagram dimanfaatkan untuk mengupdate setiap materi siaran yang akan ditayangkan. Dengan media sosial ini Cakra Semarang TV akan mendapatkan respon dari masyarakat berupa komentar, saran dan kritik yang nantinya mendapat feedback dari pihak admin Cakra Semarang TV yang digunakan untuk mengevaluasi dan meningkatkan kualitas siaran program Cakra Semarang TV.

Memanfaatkan saluran youtube channel Cakra Semarang tv, divergensi konten media akan membuat pemirsa televisi memiliki banyak pilihan dan pemirsa bebas memilih konten acara yang disukai kapan dan dimanapun.
Divergensi media dapat meningkatkan jumlah pemirsa, namun sisi lainnya perhatian pemirsa akan terbagi dengan banykanya pilihan dan loyalitas pemirsa terhadap stasiun televisi, khusunya Cakra Semarang TV.

\begin{tabular}{|l|l|}
\hline Pukul & Program Acara \\
\hline 06.10 & Jateng tourist chanel \\
\hline 06.20 & UKM chanel \\
\hline 06.30 & Kelepon \\
\hline 07.30 & Seputar Jawa Tengah Pagi \\
\hline 08.00 & Sugeng Enjang \\
\hline 08.30 & Ocydiah Home shopping \\
\hline 09.30 & Semarang Tv Shope \\
\hline 10.00 & Semarang Tv Shope \\
\hline 11.00 & Ocydiah Home shopping \\
\hline 11.30 & Seputar Jawa Tengah Siang \\
\hline 12.00 & Wayang Kulit berseri \\
\hline 13.00 & Semarang Tv Shope \\
\hline 14.00 & Ocydiah Home shopping \\
\hline 15.00 & Nyumbang Salam \\
\hline 18.30 & Seputar Jawa Tengah Malam \\
\hline 19.30 & Perwatos Jawa Tengah \\
\hline 21.00 & Semarang Tv Shope \\
\hline 21.30 & Goro-goro \\
\hline 22.00 & Mars Indonesia Raya \\
\hline 22.05 & Closing \\
\hline Tabel Jam Siar Cakra Semarang TV \\
$\begin{array}{l}\text { Channel } \\
52\end{array}$ UHF \\
\hline
\end{tabular}

Stasiun Televisi Lokal harus dapat membuat dan mengevaluasi konten siaran agar menarik dengan tidak meninggalkan ciri khas agar mampu bersaing dengan media TV lainnya. Menurut Aris Kundari selaku Koordinator Master kontrol (2020) menjelaskan bahwa upaya yang telah diterapkan Cakra Semarang TV dalam mengikuti perubahan zaman yang dinamis, dengan memanfaatkan media baru untuk menarik keinginan pemirsa. Untuk itu, diperlukan kreatifitas dan inovasi dalam setiap kegiatan penyiaran program acara televisi yang dilaksanakan. Sumber daya manusia di 
Cakra Semarang TV terus melakukan peningkatan kemapuan dan kreatifitas agar dapat memberikan pelayanan terbaik memberikan konten yang nyaman dan infromatif. Perkembangan teknologi digital yang semakin memudahkan proses penyiaran konten memberikan tantangan konsumsi konten yang terus berubah.

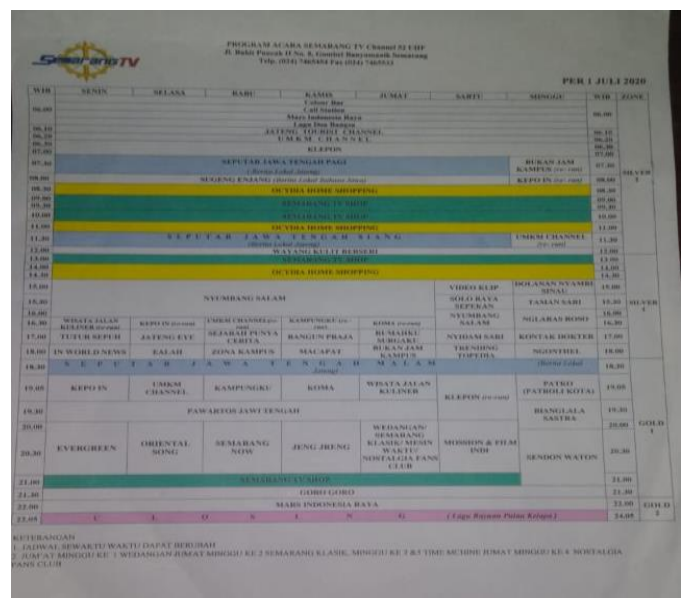

Gambar: Jam siar Cakra Semarang TV

Menurut Supriyadi Menejer Produser, Program mengatakan Cakra Semarang TV (2020) juga menggunakan facebook dan instagram hingga website yang menampilkan gambar dan teks melalui layanan daring. Program acara yang akan ditayangkan biasanya akan dipromosikan lewat media sosial diantarnya melalui instagram atau facebook Cakra Semarang TV. Dengan informasi melalui media sosial diharapkan audience dapat stay tune untuk mengikuti rangkaian program acara yang disuguhkan Cakra Semarang TV.

Cakra Semarang TV menerapkan divergensi media lainnya, pendistribusian media televisi mengalami perubahan bentuk sehingga media mainstream harus dapat memanfaatkan media youtube dan media lainnya. Penggunaan media sosial seperti instagram, facebook dan website merupakan cara media Cakra Semarang TV untuk mendekatkan diri kepada audience. Strategi dalam mempertahankan eksistensi media TV adalah memperluas saluran distribusi siaran dengan menggunakan seluruh jaringan yang ada, serta menggunakan promosi (on air) ataupun even (off air) untuk mempromosikan dan mengenalkan konten siaran Cakra Semarang TV. Menurut Al Barran dalam Doyle (2014), hadirnya layanan berbasis online, secara dramatis mengubah cara konsumen dalam berkomunikasi serta mengkonsumsi konten media televisi. Hal tersebut berimbas pada perubahan pola konsumsi media seperti menerima konten informasi dengan menggunakan perangkat gawai atau smartphone (Halim \& Sujoko, 2018).

Sumber pendapatan Cakra Semarang TV mengandalkan program acara untuk mendapatkan pemasukan. Program-program tersebut menampilkan para klien yang merupakan pengiklan maupun pihak yang telah bekerjasama, yaitu pihak swasta maupun pemerintah daerah. Karena pasar iklan yang sepi di ranah lokal, iklan bukan menjadi andalan utama dari Cakra Semarang TV untuk memperoleh pendapatan, melainkan menjual program, yang kliennya sendiri merupakan audience atau penontonnya. Sementara akun youtube menurut Agung Mujiono masih belum mendatangakn keuntungan signifikan dari proses monetizes. Era teknologi menuntut media konvensional meningkatkan inovasi, seperti media cetak yang beralih ke e-paper, adaptasi 
perilaku konsumen yang lebih banyak menggunakan teknologi (Putra, 2019).

Cakra Semarang TV memposisikan diri sebagai televisi lokal yang berbasis budaya Jawa Tengah memiliki segmentasi pasar terbatas seputaran isu atau produksi lokal sebagai penarik pembaca. Keunggulan dari segi teknologi dibanding dengan Tv lokal lainnya, Cakra terus meningkatkan kualitas program dengan baik.

\section{Kesimpulan}

Era Disrupsi dan pandemi covid 19 saat ini Cakra Semarang TV sebagai salah satu Televisi lokal Di Ja wa Tengah merasakandampak sangat besar terutama dalam hal pendapatan iklan. Semakin ketatnya persaingan antar media elektronik khususnya televisi lokal membuat Cakra TV harus dapat membuat konten yang menarik dengan membawa kearifan lokal khususnya tradisi budaya Jawa Tengah walaupun hal tersebut juga terdapat kendala. CakraTV tidak hanya bersaing dengan televise local lain, melainkan juga dengan televisi nasional ataupun media baru lainnya seperti media online, youtube, dan media sosial. Sumber pendapatan Iklan bukan lagi menjadi andalan bagi Cakra Semarang TV untuk meraih pendapatan, disebabkan banyak pengusaha lokal maupun nasional sangat sedikit beriklan dalam mempercayakan produknya untuk diiklankan di televisi lokal pada masa sekarang.

\section{Referensi}

Abdullah, A., \& Puspitasari, L. (2018). Media Televisi Di Era Internet. ProTVF, 2(1), 101. https://doi.org/https://doi.org/10.241 98/ptvf.v2i1.19880

Agung, P. (2012). Era Penyiaran Digital : Pengembangan atau Pemberangusan TV Lokal dan TV Komunitas? Jurnal Komunikasi, 1, 301-314.

Christensen, C. M. (1997). The Innovator's Dilemma: When Technologies Cause Great Firms to Fail. Boston: Harvard Business School Press.

Doyle, G. (2014). Media Ownership: Diversity Versus Efficiency in a Changing Technological Environment. Handbook of the Economics of Art and Culture., 2.

Flew, T. (2005). New Media, and Introduction. United Kingdom: Oxford University Press.

Halim, S. (2018). Penerapan Konvergensi dan Divergensi TV9 Lombok di Era Disrupsi. KOMUNIKA: Jurnal Dakwah Dan Komunikasi, 12(2), 275-289.

Halim, S., \& Sujoko, A. (2018). Strategi Stasiun Tv9 Lombok di Era Disrupsi. x(2), 153-170.

Harmoko, M. (2020). Porsi Konten Pemberitaan.

Karman. (2017). Disruptif Teknologi Internet Dan Eksistensi Media Cetak. 9, 182-192.

Kundari, A. (2020). Semarang TV: Dinamika Media Baru.

Mujiono, A. (2020). Pesan Streaming Youtube, website, Semarangtv.tv.

Ohoitimur, J. (2018). Disrupsi:Tantangan bagi

Perkembangan Ilmu Pengetahuan dan Peluang bagi Lembaga Pendidikan Tinggi. Respons. 23(2), 143-166.

Putra, R. A. (2019). Tantangan Media Massa Dalam Menghadapi Era 
Disrupsi Teknologi Informasi.

Jusifo, 5(1), 1-6.

https://doi.org/https://doi.org/10.191

09/jusifo.v5i1.5003v

Ramadhanty, L. (2019). Strategi

Branding TVRI di Era Disrupsi

Teknologi dalam Mengembangkan

Reputasi Sebagai Lembaga

Penyiaran Publik. Mercu Buana.

Rusadi, U. (2014). Konsumsi Berita

Lintas Media Massa Konvensional

Dan Internet News Consumption

Across Conventional Mass Media

And The Internet. Jurnal Penelitian

Dan Pengembangan Komunikasi

Dan Informatika, 4(3), 173-187.

Saptya, R., \& Permana, M. (2029).

Strategi Pemanfaatan Media Baru

Net . Tv Utilization Oo New Media

Strategy of Net ., 21-36.

Supriyadi. (2020). Penggunaan Media

Baru.

Weber, J., \& Newberry, T. (2007). No

Title. In IPTV Crash Course. New

York. 